\title{
PAXX and XIf interplay revealed by impaired CNS development and immunodeficiency of double KO mice
}

\author{
Vincent Abramowski ${ }^{1,7}$, Olivier Etienne ${ }^{2,7}$, Ramy Elsaid ${ }^{3,4,5,7}$, Junjie Yang ${ }^{3,4,5,7}$, Aurélie Berland ${ }^{1}$, Laetitia Kermasson ${ }^{1}$, Benoit Roch', \\ Stefania Musilli ${ }^{1}$, Jean-Paul Moussu ${ }^{6}$, Karelia Lipson-Ruffert ${ }^{6}$, Patrick Revy ${ }^{1}$, Ana Cumano ${ }^{3,4,5}$, François D Boussin ${ }^{2}$ and \\ Jean-Pierre de Villartay ${ }^{\star 1}$
}

The repair of DNA double-stranded breaks (DNAdsb) through non-homologous end joining (NHEJ) is a prerequisite for the proper development of the central nervous system and the adaptive immune system. Yet, mice with XIf or PAXX loss of function are viable and present with very mild immune phenotypes, although their lymphoid cells are sensitive to ionizing radiation attesting for the role of these factors in NHEJ. In contrast, we show here that mice defective for both XIf and PAXX are embryonically lethal owing to a massive apoptosis of post-mitotic neurons, a situation reminiscent to XRCC4 or DNA Ligase IV KO conditions. The development of the adaptive immune system in $\mathrm{XIf}^{-1-} \mathrm{PAXX}^{-/}$E18.5 embryos is severely affected with the block of $\mathrm{B}$ - and T-cell maturation at the stage of $\operatorname{lgH}$ and TCR $\beta$ gene rearrangements, respectively. This damaging phenotype highlights the functional nexus between XIf and PAXX, which is critical for the completion of NHEJ-dependent mechanisms during mouse development.

Cell Death and Differentiation (2018) 25, 444-452; doi:10.1038/cdd.2017.184; published online 27 October 2017

All living organisms are subjected to multitude sources of DNA damage during their lifespan, either as a result of external assault or endogenous physiological processes. ${ }^{1}$ Among endogenous sources of physiological DNAdsb is the somatic rearrangement of immunoglobulin $(\mathrm{lg})$ and TCR genes in B and $T$ lymphocytes, respectively, during the diversification of the adaptive immune system through $\mathrm{V}(\mathrm{D}) \mathrm{J}$ recombination. ${ }^{2}$ DNA double-stranded breaks (DNAdsb) are considered the most toxic lesions. DNAdsbs are repaired by two main mechanisms: the homologous recombination (HR) in cycling cells, when a sister chromatid is available as DNA repair template, and the non-homologous end joining (NHEJ) during all phases of the cell cycle.

NHEJ proceeds via the simple religation of DNA ends without the need for a repair template. ${ }^{3}$ Briefly, the NHEJ is composed of seven core factors comprising the Ku70/80/ DNA-PKcs (DNA-dependent protein kinase catalytic subunit) complex, which recognizes and protects the broken DNA ends, the Artemis endo/exonuclease, which participates, when needed, in processing the DNA ends and the XRCC4/ DNA-Ligase IV/XIf complex, which ultimately reseals the DNA break. The critical function of the NHEJ apparatus in various aspects of higher eukaryote development has been extensively perceived in several animal and human pathological conditions. As emblematic examples, loss of function of either XRCC4 or DNA ligase IV results in embryonic lethality in mice ${ }^{4,5}$ and mutations in Artemis or DNA-PKcs result in severe combined immunodeficiency conditions in both men and mice, owing to aborted V(D)J recombination. ${ }^{6}$ In addition, defects in
NHEJ results in genetic instability and the propensity to develop various types of cancers, notably leukemia and lymphomas. ${ }^{7}$

Recently, a new DNA repair factor, PAXX (PAralog of XRCC4 and XIf, also known as C9orf142 or XLS), has been identified independently by three laboratories based on bioinformatics and biochemistry approaches. ${ }^{8-10}$ PAXX belongs to the XRCC4 superfamily and shows structural similarities with both XRCC4 and XIf. PAXX is recruited to DNAdsb and is a physical interactor of the Ku/DNAPK complex, notably through its interaction with Ku70. ${ }^{11}$ Surprisingly, for a NHEJ factor, the deficiency of PAXX does not systematically result in an increased sensitivity to ionizing radiation (IR) and the results of the various DNA repair assays are highly controversial, depending on the experimental settings. $^{8-10,12-15}$ This suggested a possible functional complementation of PAXX deficiency in certain conditions.

To analyze the role of PAXX during mouse development in vivo and identify a possible redundant function with another DNA repair factor, we created CRISPR/Cas9 PAXX mutant mouse lines. Although the sole inactivation of PAXX did not result in an overwhelming phenotype, the concomitant deletion of PAXX and XIf had severe consequences resulting in embryonic lethality and arrest of $V(D) J$ recombination in embryos. Altogether, these results are consistent with PAXX being a bona fide NHEJ factor and highlight the critical functional interplay between PAXX and XIf during mouse development.

\footnotetext{
1'Laboratory "Genome Dynamics in the Immune System", INSERM UMR1163, Université Paris Descartes Sorbonne Paris Cité, Institut Imagine, Paris, France; '2Laboratoire de Radiopathologie, UMR 967, DRF, CEA-INSERM-Université Paris Diderot-Université Paris Sud, Fontenay-aux-Roses, Paris, France; ${ }^{3}$ Lymphopoiesis Unit, Department of Immunology, Institut Pasteur, Paris, France; ${ }^{4}$ University Paris Diderot, Sorbonne Paris Cité, Cellule Pasteur, Paris, France; ${ }^{5}$ INSERM U1223, Paris, France and ${ }^{6}$ SEAT-TAAM CNRS Phenomin UPS44, Villejuif, France

*Corresponding author: Dr J-P de Villartay, Laboratory "Genome Dynamics in the Immune System", INSERM UMR1163, Equipe Labellisée Ligue Contre le Cancer Institut Imagine, 24 bd du Montparnasse, 75015 Paris, France. Tel: +33 1427542 93; E-mail: devillartay@gmail.com

${ }^{7}$ These authors contributed equally to this work

Received 03.7.17; revised 19.9.17; accepted 21.9.17; Edited by H-U Simon; published online 27.10.17
} 


\section{Results and discussion}

Generation of PAXX KO mice. PAXX KO mice were generated using CRISPR/Cas9. Two guide RNA target sequences were selected in exon 1 (PAXX1) and exon 2 (PAXX2) of the murine PAXX gene (Figure 1a and Supplementary Figure S1A). The efficacy of the two gRNA was scored through the disappearance of restriction sites $\mathrm{BsrBI}$ and Sacl upon transfection of MEFs with the pX330 vector expressing the gRNAs and Cas9 (Supplementary Figure S1B). To generate mutant mouse lines, zygotes were microinjected with pX330 according to the protocol of Mashiko et al. ${ }^{16}$ Thirteen and five F0 mice were obtained for PAXX1 and PAXX2, respectively. Tail DNA was analyzed by $P C R$ and restriction digest (PCR-RE) to identify four PAXX1 and two PAXX2 F0 mutant mice showing clear retention of undigested DNA above background (Supplementary Figure S1C). F0 mice were crossed onto $\mathrm{C} 57 \mathrm{BI} / 6$ to segregate the various CRISPR/Cas9-generated mutant alleles. Two F0-derived F1 mice, \#2 for PAXX1 and \#14 were selected upon direct DNA sequencing of the mutant alleles. CRISPR/Cas9 mutagenesis resulted in an 8-bp deletion and subsequent frameshift in both cases (Figure 1a). Each line was backcrossed up to six times on
C57BI/6 to segregate away any off-target event outside of chromosome 2. Homozygous mutant mice were obtained by intercross of either $\mathrm{PAXX} 1^{+/-}$or $\mathrm{PAXX} 2^{+/-}$heterozygous founders. Homozygous mice were viable and were produced at Mendelian frequencies ruling out a major effect of PAXX deficiency during embryogenesis. The loss of function of the CRISPR/Cas9-generated PAXX mutant allele were ascertained by western blotting using protein extracts from thymus, spleen, and MEFs from PAXX2 mouse line. As shown in Figure 1b, PAXX protein expression was undetectable in $\mathrm{PAXX} 2^{-/}$mice, in contrast to wild-type littermates. We conclude that CRISPR/Cas9 mutagenesis resulted in complete PAXX loss of function.

Normal development of the immune system in PAXX KO mice. Proficiency of the DNA Damage Response (DDR) machinery, in particular the NHEJ pathway, is critical for the appropriate development of B and T lymphocytes, owing to the generation of DNAdsb during the somatic DNA rearrangement of both $\mathrm{Ig}$ and TCR genes. ${ }^{6}$ Nevertheless, XIf deficiency does not have a severe impact on the $V(D) J$ recombination process and XIf-deficient mice present with a very mild defect in their immune system, characterized mainly by a slight reduction in lymphocyte numbers and an a PAXX1 (del 8bp)

wт TGCTACTGCGAGCGGGATAGTGGTGGAGACG Mut. TGCTACTGCGAG--------TGGTGGAGACG PAXX2

\section{(del 8bp)}

wт TGACGGACGCCGCCGAGCTCTGGAGCACCTG Mut. TGACGGACGCCGCCGAGC--------ACCTG b

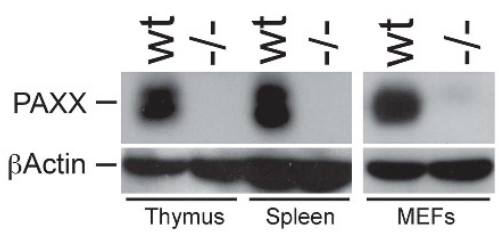

C

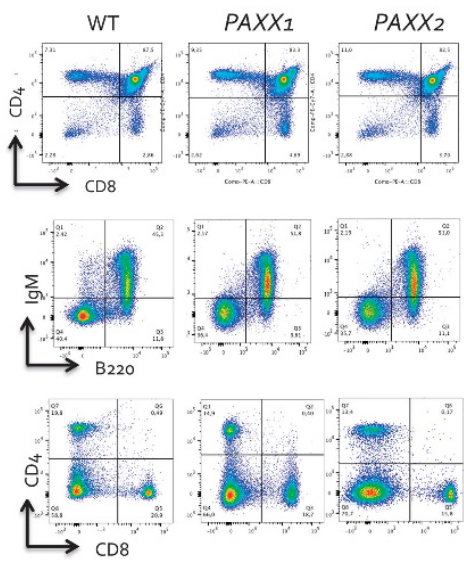

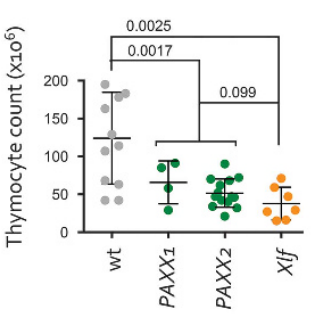

d

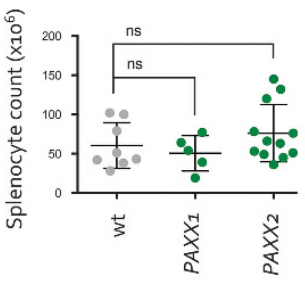

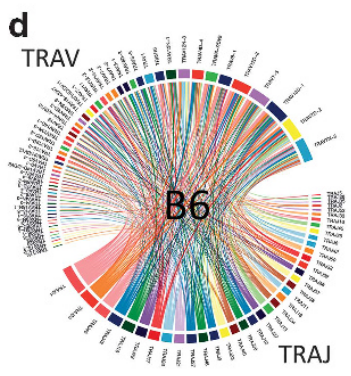
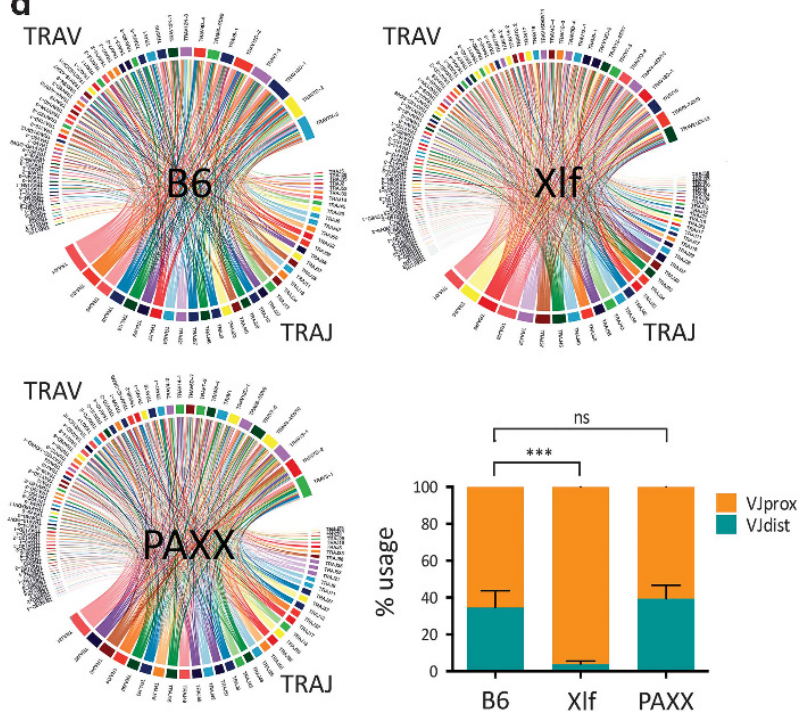

Figure 1 Design and immunophenotyping of PAXX KO mice. (a) Design of gRNA used to create CRISPR/Cas9 mutations in the PAXX gene. The BsrBI and Sacl restriction enzyme sites used to screen for mutagenesis are underlined. The two lines PAXX1 and PAXX2 harbor an 8-bp deletion resulting in frameshift. (b) Western blot analysis confirming the PAXX loss of function in PAXX2 mutant mice, with the absent protein in the thymus, spleen, and MEFs. (c) Immunophenotyping of wt. $(N=11)$, PAXX1 ( $N=4)$, PAXX2 $(N=12)$, and XIf $(N=7)$ mice. FACS representation of thymocytes and splenocytes and representation of absolute count numbers. (d) Illustrative Circos-plot representations of TCR $\alpha$ repertoire in thymocytes from C57BI/6, XIf, and PAXX2 mice. Each chord line represents the association between one TRAV and one TRAJ segment as determined by TCR $\alpha$ transcript sequencing. Quantification of TCR $\alpha$ TRAV gene usage in C57BI/6, Xlf, and PAXX2 mice. TCR $\alpha$ repertoire determination was repeated two times using an overall six PAXX2 KO, five C57BI/6, and six XIf KO mice. Statistical analyses were performed using Mann-Whitney non-parametric t-test using Prism v6 (** $P<0.001)$ 
increased in thymocyte apoptosis. ${ }^{17,18}$ Qualitatively, this translates into a skewing in the TCRa repertoire with the under-representation of distal TRAV and TRAJ gene segments. ${ }^{17}$ Analysis of the immune system in both PAXX1 and PAXX2 KO mice revealed an overall normal development of $\mathrm{T}$ cells in the thymus, despite a statistically significant reduction in thymocyte numbers in the range of what observed in XIf mice (Figure 1c). Mature B- and T-cell numbers in the spleen were comparable between PAXX mice and WT littermates. This is in general agreement with previously described PAXX mutant mice. ${ }^{12,15}$ Analysis of the TCR $a$ repertoire through 5' RACE RT-PCR and nextgeneration sequencing revealed a well-diversified TCRa repertoire in PAXX mice, comparable to WT and XIf animals (Figure 1d). However, in contrast to the important decrease in distal VaJa usage in XIf thymocytes as previously described, ${ }^{17}$ thymocytes from PAXX mice did not show any skewing in the representation of these TCRa gene segments.
From these observations, we conclude that PAXX loss of function does not have any detrimental impact on the $V(D) J$ recombination process and/or the overall viability of thymocytes.

DNAdsb repair defect in PAXX KO mice. Given its homology with both XRCC4 and XIf, PAXX is thought to intervene during DNA repair through NHEJ. ${ }^{8-10} \mathrm{~T}$ lymphocytes isolated from blood or spleen are mainly non-cycling resting cells which, as a result, utilize NHEJ to cope with DNAdsb when HR is operational only in cycling cells. We set up to analyze the role of PAXX during NHEJ through the survey of splenic T-cell sensitivity to IRs (Figure $2 a$ ). Ex vivo isolated resting splenic mature $T$ cells were subjected to various doses of IR ( $0-4 \mathrm{~Gy}$ ). After $4 \mathrm{~h}$ of recovery to allow for repair of IR-induced DNAdsb, cells were incubated with antiCD3/anti-CD28-coated beads during 4 days, which activates and induces a strong proliferative response of $\mathrm{T}$ lymphocytes

a
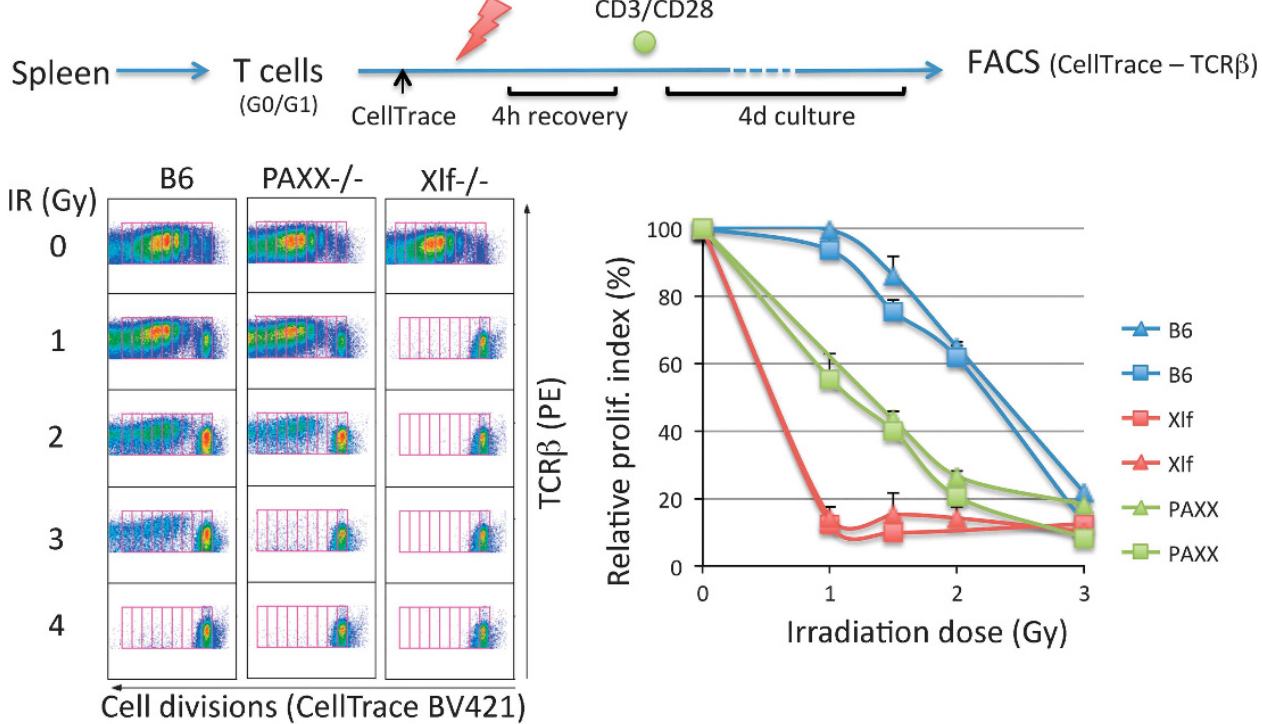

b
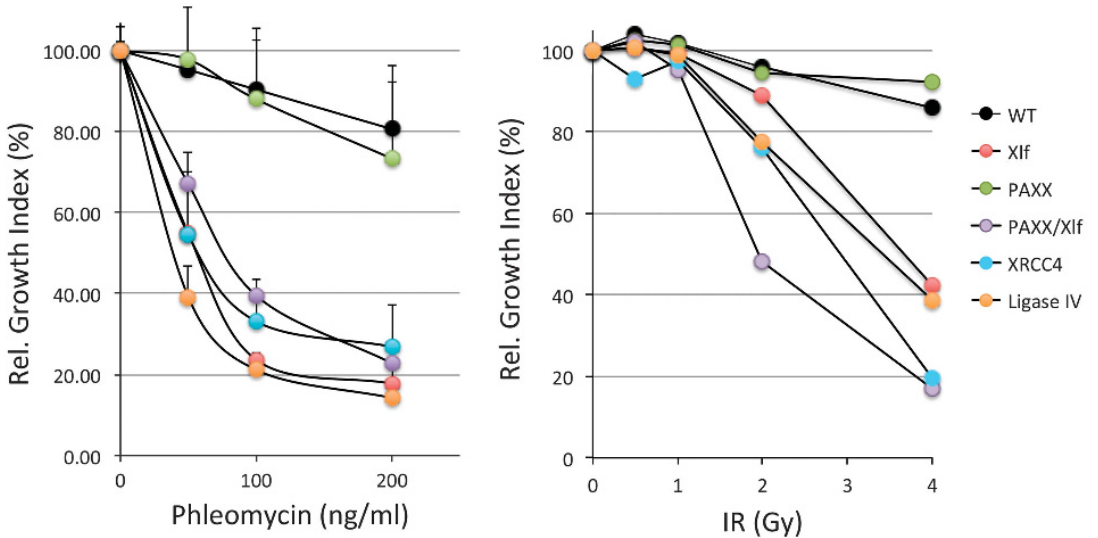

Figure 2 DNA repair defect in PAXX KO mice. (a) Radiosensitivity assay performed on mature splenic T lymphocytes. For FACS analysis, doubling populations were scored in gates defined by the dilution of the CellTrace signal and the proliferative index calculated according to Roederer. ${ }^{26}$ The relative proliferative indexes were plotted for each sample according to the proliferation in the absence of IR and used to define the radiosensitivity level. The experiment was repeated twice with two mice per genotype each time. (b) Phleomycin and IR sensitivity on SV40-transformed MEFs. MEFs from XRCC4, DNA-Ligase IV, and XIf KO mice were used as radiosensitive controls. The relative growth indexes were calculated by comparing the confluence of treated cells and non-treated cells during culture with real-time Incucyte monitoring (see Materials and Methods). This experiment was repeated three times 
that can be readily quantified through the dilution of the CellTrace dye upon cell divisions. We used this readout as a mean to score the relative index of proliferation, and hence the cell survival, following IR. Using this protocol, T cells from XIf mice showed an extreme sensitivity to IR as compared with WT (Figure 2a) with a fall in cell survival already at the first dose of $1 \mathrm{~Gy}$, as expected for XIf deficiency. PAXXdeficient $\mathrm{T}$ lymphocytes were also strikingly radiosensitive, although to a lesser extent than XIf-defective $T$ cells. In contrast, murine embryonic fibroblasts (MEFs) derived from PAXX mutants were resistant to either IR or the DNAdsb inducer Phleomycin with cell survival comparable to that of WT MEFs (Figure 2b), whereas MEFs defective for XRCC4, DNA-Ligase IV, or XIf were highly sensitive as expected. This is in accord with the previously noted mild sensitivity of $\mathrm{PAXX}^{-/}$MEFs to $\mathrm{IR}^{15}$ but contrasts with the results from Balmus et al. ${ }^{12}$ Ever since the identification of PAXX by three different groups, its implication in the DDR as judged by the sensitivity to genotoxic drugs or IR has been highly controversial, depending on the cell line analyzed in vitro, the experimental conditions, and the drugs used to inflict DNA damage. ${ }^{8-10}$ Interestingly, asynchronous PAXXdefective $\mathrm{CH} 12$ B-cell lines or v-Abl-transformed Pro-B-cell lines do not demonstrate any IR sensitivity above that of their wt counterparts, as we found in MEFs, and the concomitant PAXX and XIf deficiency does not worsen the sensitivity caused by XIf mutation alone in these cycling cells. ${ }^{13}$ In contrast, the synchronization of $\mathrm{PAXX}^{-/-} / \mathrm{XIf}^{-/-} \mathrm{V}-\mathrm{Abl}$ pro-B cells into the G1 phase of the cell cycle with either STI-571 (vAbl kinase inhibitor) or PD033991 (CDK4/6 inhibitor) results in an extreme sensitivity to IR, well beyond that of $\mathrm{XIf}^{-/-}$ single mutants in the same conditions arguing for a unique role of PAXX in classical NHEJ when DNA damage occurs in G1, hence in the absence of functional HR. Our observation of an IR sensitivity of small resting, ex vivo purified $T$ lymphocytes from $\mathrm{PAXX}^{-1-}$ mice concords with this conclusion of a specific role of PAXX during C-NHEJ.

PAXX-XIf interplay during neuronal development. We next set up to evaluate the possible functional relationship between PAXX and XIf during the DNA damage response (DDR) by generating doubly deficient mice through intercrossing either $\mathrm{PAXX}^{-/-} \mathrm{XIf}^{+/-}$or $\mathrm{PAXX}^{+/-} \mathrm{XIf}^{-1-}$ animals. In no instance did we obtain $\mathrm{PAXX} \mathrm{X}^{-1-} / \mathrm{XIf}^{-/-}$mice on a total of 176 newborns (44 PAXX1 and 132 PAXX2) obtained from crosses of various genotype combinations for which about 31 (11 PAXX1 and 20 PAXX2) were expected to harbor the $\mathrm{PAXX}^{-1-} / \mathrm{XIf}^{-/-} \mathrm{DKO}$ genotype, arguing for an embryonic lethality of the concomitant inactivation of both factors (Figure 3a) as previously noted in two different studies. ${ }^{12,15}$ The embryonic lethality was observed with both PAXX1 and PAXX2 mutant lines, excluding an off-target effect as responsible for this phenotype. Lived DKO embryos could be readily obtained in E18.5 mice downward (Figure $3 b$ ) arguing for a late embryonic lethality of DKO animals, similar to the previously described late embryonic lethality of XRCC4 and DNA Ligase IV KO mice. ${ }^{4,5}$ Nevertheless, embryos at E18.5 usually appeared smaller than their heterozygous littermates (Figure $3 b$ ), confirming their overall abnormal development. The lethality of PAXX/XIf DKO embryos was to us the first evidence of a functional interplay between PAXX and XIf, the co-inactivation of which results in a major viability phenotype, when both single mutants do not present evidence for developmental defect (this study and Vera et $a l^{17}$ ). In XRCC4 and DNA-Ligase IV KO mice, the embryonic lethality is caused by the massive apoptosis of post-mitotic neurons. ${ }^{4,5}$ Likewise, the presence of numerous pyknotic nuclei and the cleaved-caspase 3 (CC3) immunostaining ${ }^{19}$ revealed a severe neuronal apoptosis in the brain of $\mathrm{XIf}^{-1-} \mathrm{PAXX} \mathrm{X}^{-1-}$ embryos (Figures 3c-e, Supplementary Figure S3) as previously reported. ${ }^{12,15}$ This contrasted with the scarce apoptotic cells in the brains of $\mathrm{XIf}^{-/-}$embryos and their absence in that of $\mathrm{PAXX}^{-/-}$ embryos (Figures $3 c-e$, and Supplementary Figure S3A). The observation of a massive neuronal apoptosis in $\mathrm{PAXX}^{-1-} \mathrm{XIf}^{-1-}$ DKO whatever the type of PAXX1 or PAXX2 mutants used in intercrosses again ruled out a CRISPR/Cas9 off-target effect as responsible for this phenotype. Although apoptosis was detected in the regions where neural progenitors proliferate (that is, the ventricular (VZ) and subventricular zones (SVZ), surrounding the lateral hemispheres), it was most prominent in the regions that contain post-mitotic neurons. Indeed, consistent with the kinetics of neuronal production in the different brain structures, apoptosis was predominantly found in the ventral telencephalon at E12.5 (Figure 3a) and in the dorsal telencephalon at E15.5 (Figures $3 b$ and c and Supplementary Figure S3B).

PAXX-XIf interplay during lymphoid development. The profound impact of the concomitant deletion of PAXX and XIf on the development of the central nervous system, resulting in late embryonic lethality, is highly reminiscent of both XRCC4 and DNA Ligase IV-deficient conditions, in which NHEJ is severely affected. ${ }^{4,5}$ As a major defect in the development of the immune system is also one typical feature of these NHEJ-deficient murine models, we aimed at analyzing this question qualitatively and quantitatively in $\mathrm{XIf}^{-l-} \mathrm{PAXX} \mathrm{X}^{-1-}$ DKO embryos. TCR gene rearrangements begin around $\mathrm{E} 13$ and thymuses are easily recovered at E18.5, the gestation day we choose for this analysis. At E18.5, thymuses from wt mice contained $1.71 \times 10^{6}$ thymocytes on average (Figures $4 a$ and $b$ ), a number that was not affected by the deletion of PAXX alone $\left(1.84 \times 10^{6}\right)$ but was significantly reduced around twofold in the context of XIf KO $\left(0.9 \times 10^{6}, P<0.0001\right)$ as previously found in thymuses from 6 - to 8 -week-old mutant mice. ${ }^{17,18}$ Strikingly, $\mathrm{XIf}^{-/-} \mathrm{PAXX}{ }^{-/-}$ embryos exhibited a 10-fold decrease in thymocyte number $\left(1.7 \times 10^{5}, P<0.0001\right)$. This reduction in the total numbers of thymocytes was mainly accounted for by the loss of CD4+ CD8+ double-positive (DP) thymocytes in $\mathrm{XIf}^{-/-} \mathrm{PAXX} \mathrm{X}^{-1-}$ mice when compared with wt mice $\left(7.40 \times 10^{3}\right.$ versus $\left.7.75 \times 10^{5}, P<0.0001\right)$, arguing for an abnormal maturation process. CD4-CD8 - double-negative (DN) thymocytes, which precede the maturation to DP, can be further divided into various populations according to their differential expression of the CD44, CD25, and CD28 surface markers. $^{20}$ In particular, the CD44-CD25+CD28+ (DN3b) fraction represents thymocytes that have undergone $\beta$ selection upon successful rearrangement of their TCR- $\beta$ locus. They will subsequently progress to DN3c, DN4a, and 
a
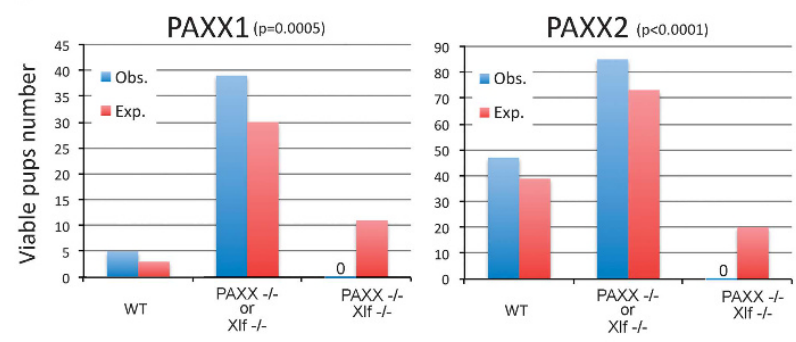

c

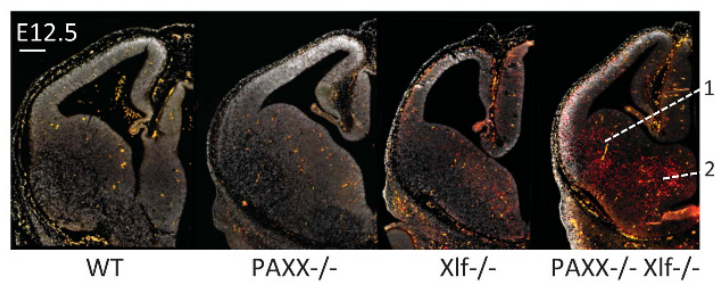

d

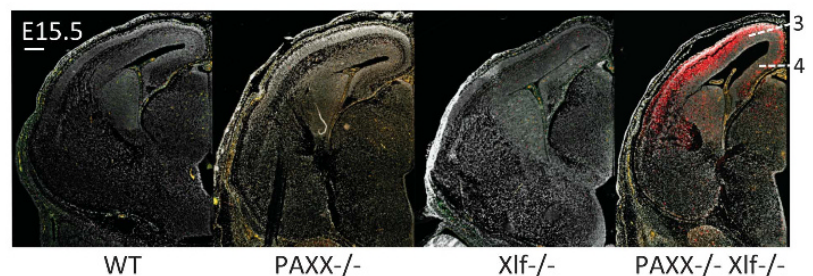

b

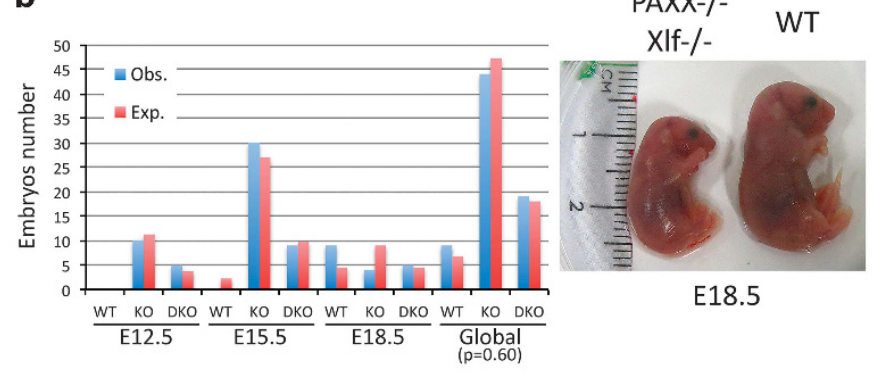

e

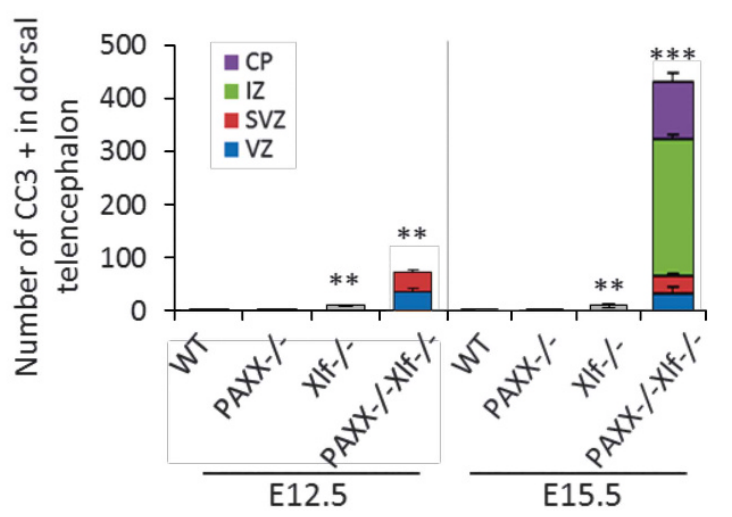

Figure 3 Embryonic lethality and massive neuronal apoptosis in PAXX ${ }^{-/-} \mathrm{XIf}^{-/-}$embryos. (a) Impaired development of PAXX ${ }^{-/}$XIf ${ }^{-/-}$DKO mice. No DKO mice were born from various combinations of PAXX1 or PAXX2 and Xlf crosses (44 and 132 pups, respectively). Statistical significance of the differences between the observed (Obs.) and expected (Exp.) genotype distributions was assessed by $\chi^{2}$-test. (b) Survival of PAXX ${ }^{-/} \mathrm{XIf}^{-/}$embryos up to E18.5. Photograph showing the reduced size of PAXX ${ }^{-/-}$XIf ${ }^{-/}$ E18.5 embryos. (c and d) Coronal sections of cerebral hemispheres of wt., $\mathrm{PAXX}^{-/-}, \mathrm{XIf}^{-/-}$, and PAXX ${ }^{-/-} \mathrm{XIf}^{-/-}$embryos collected at E12.5 (c) and E15.5 (d) and stained with 4'6-Diamidino-2-phenylindole (DAPI; gray) and CC3 (red). Blood vessels are colored in orange. Scale bars: $200 \mu \mathrm{m}$. (c) At E12.5, apoptosis in PAXX ${ }^{-1-} \mathrm{XIf}^{-/-}$embryos is massively detected in the intermediate zones (IZs) of the ganglionic eminences $(1,2)$ containing newly generated neurons for the striatum and the globus pallidus. (d) At E15.5, apoptosis in PAXX ${ }^{--} \mathrm{XIf}^{-/-}$embryos is predominant in the IZ and the cortical plates (CPs) of the dorsal telencephalon containing newly generated post-mitotic neurons of the neocortex (3) and the hippocampus (4). (e) The bar graph shows the mean numbers per cortical slice of cleaved-caspase-3-positive cells \pm S.D. detected in the ventricular zone (VZ), subventricular zone (SVZ), IZ, and CP of the neocortex of wt., PAXX ${ }^{-/}, \mathrm{XIf}^{-/-}$, and PAXX ${ }^{-/-} \mathrm{XIf}^{-/-}$embryos at E12.5 and E15.5. Data have been obtained from at least three embryos per group. Stars indicate the statistical significance in comparison to the wt controls. ${ }^{* \star} P \leq 0.01,{ }^{* \star *} P \leq 0.001$; Mann-Whitney test

DN4b, and ultimately to DP as depicted in Figure 4a. Analyses of these archetypical thymocyte populations in $\mathrm{XIf}^{-I-} \mathrm{PAXX}^{-1-}$ DKO E18.5 embryos revealed a major block at the transition DN3a to DN3b (Figures 4a and b), resulting in a significant decrease in the number of thymocytes from DN3b stage onward when compared with wt mice $\left(1.3 \times 10^{4}\right.$ versus $\left.8.3 \times 10^{4}, P<0.0001\right)$. This developmental arrest at the critical step of $\beta$-selection strongly suggested a possible impairment of $V(D) J$ recombination at the TCR- $\beta$ locus in thymocytes from $\mathrm{XIf}^{-1-} \mathrm{PAXX}{ }^{-1-}$ embryos. TCR- $\beta$ rearrangements involving $\mathrm{V} \beta_{10}$ and the $\mathrm{D} \beta_{2}-\mathrm{J} \beta_{2}$ cluster were analyzed by PCR in thymocytes from mice with various genotypes as depicted in Figure 4c. Rearrangements of $\mathrm{D} \beta_{2}$ or $\mathrm{V} \beta_{10} \mathrm{D} \beta_{2}$ segments to $\mathrm{J} \beta_{2}$ elements resulted in a ladder of PCR products identified by an intronic $3^{\prime} J \beta_{2}$ probe the length of which depends on the $J \beta_{2}$ element utilized during the recombination process. No detectable PCR product corresponding to either $D \beta_{2} J \beta$ or $V \beta_{10} D \beta_{2} J \beta$ rearrangements could be detected in DNA from $\mathrm{XIf}^{-1-} \mathrm{PAXX}{ }^{-1-}$ thymocytes (Figure 4c, lanes 8, 9,16, and 20), although they were readily identified in PAXX and Xlf single KO mice, attesting for the severely impaired $\mathrm{V}(\mathrm{D}) \mathrm{J}$ recombination process in the concomitant absence of PAXX and XIf.

B-cell maturation in fetus takes place in the fetal liver (FL) with rearrangement and expression of the Ig heavy chain locus occurring around E17.5 at which time $\mu \mathrm{H}$ chain becomes detectable intracellularly. ${ }^{21} \mathrm{CD} 19+\mathrm{B} 220+\mathrm{B}$-lineage cells were present in the FL of WT, $\mathrm{XIf}^{-1-}$ and $\mathrm{PAXX}{ }^{-1-} \mathrm{XIf}^{-1-} \mathrm{E} 18.5$ embryos, attesting for the normal B-cell lineage commitment in all conditions (Figure $5 \mathrm{a}$ ). However, whereas $20 \%$ of CD43 $+\mathrm{B} 220+$ pro-B cells expressed the intracytoplasmic $\mu \mathrm{H}$ chain (ilgM) in $\mathrm{FL}$ of littermates $\mathrm{PAXX}+-\mathrm{XIf}^{+/}$embryos, this population represented only $5 \%$ of the CD43+B220+ population in the PAXX ${ }^{-1-} \mathrm{XIf}^{-1-}$ DKO embryos (Figures $5 \mathrm{a}$ and $\mathrm{b}$ ), attesting for a major defect in either rearrangement or expression of the IgH locus in these embryos. Interestingly, a gradient of severity of this phenotype followed the severity of the genotype involved with a statistically significant contribution of XIf KO on its own (Figure 5b). This could also be noticed in the fetal thymus with the partial block of $\mathrm{XIf}^{-1-}$ thymocytes at the DN3a stage when compared with wt embryos (Figure 4a). As for TCR $\beta$ rearragement in the thymus, we used a PCR approach to analyze the recombination of the $\mathrm{IgH}$ locus in 
a
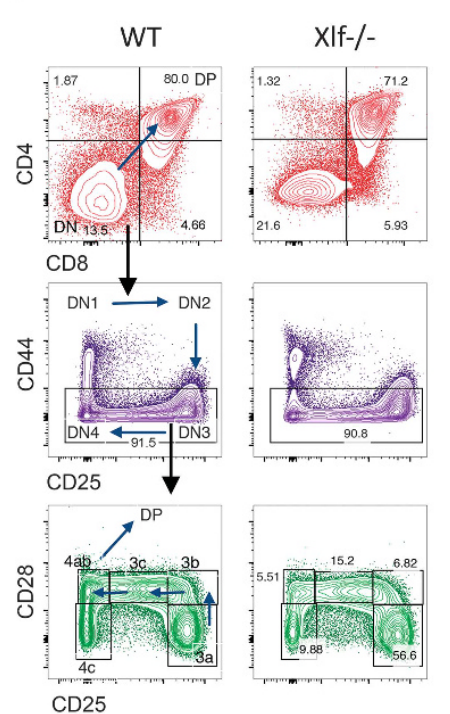

CD25

b Total thymocytes

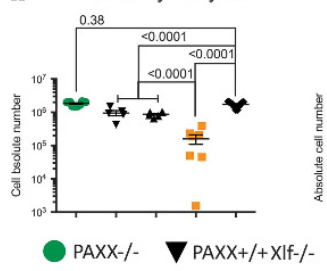

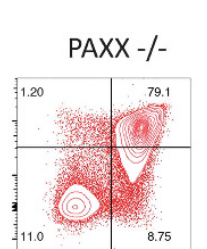
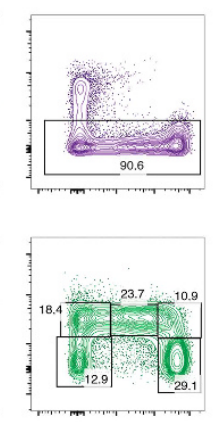

DP

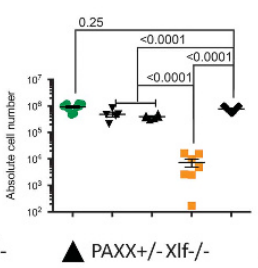

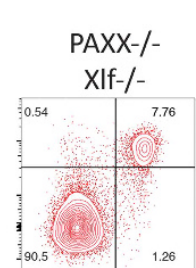
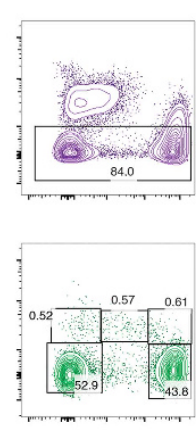

DN3bcDN4ab

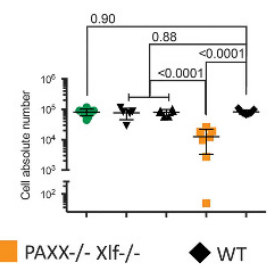

c
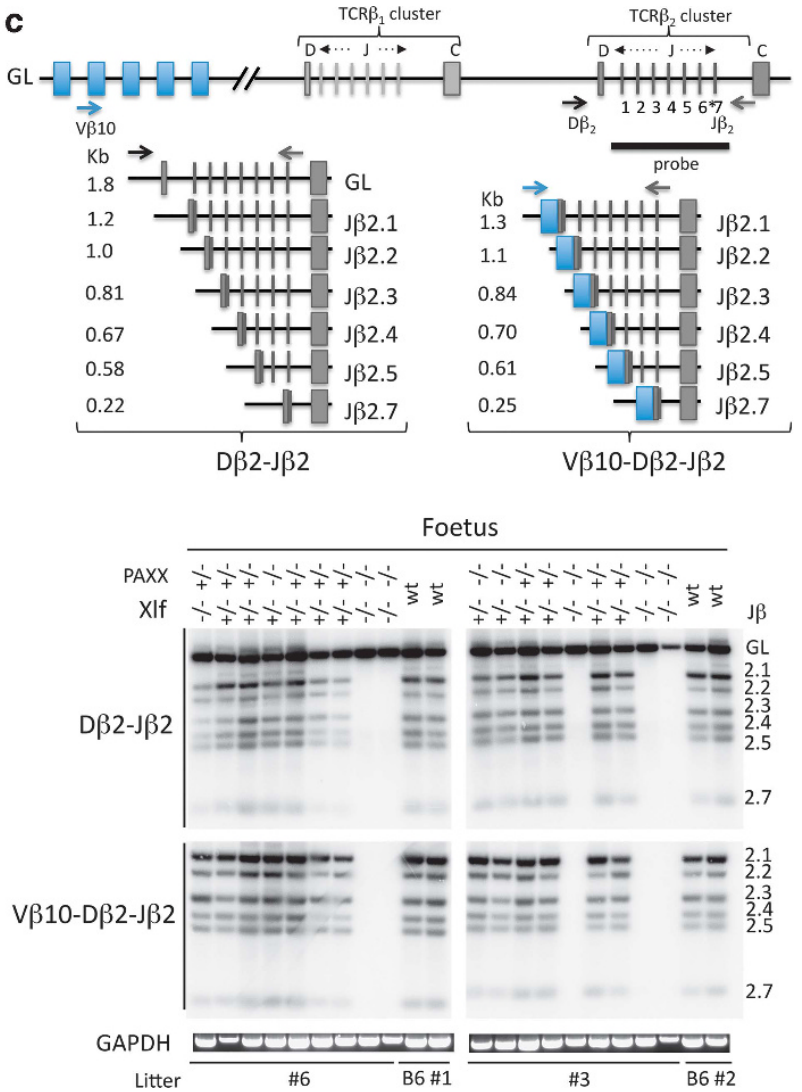

Figure $4 \mathrm{~V}(\mathrm{D}) \mathrm{J}$ recombination defect and impaired development of thymocytes in PAXX-1-/XIf ${ }^{-1-}$ E18.5 embryos. (a) Immunostaining of thymocytes from wt, XIf ${ }^{-1-}$, $\mathrm{PAXX}^{-1-}$, and PAXX ${ }^{-1-} \mathrm{XIf}^{-1-}$ E18.5 embryos. Upper panel (red) shows the important decrease in CD4 $4^{+} \mathrm{CD} 8^{+} \mathrm{DP}$ in the thymus from PAXX ${ }^{-1-} \mathrm{XIf}^{-1-} \mathrm{embry}^{-}$. DN (CD4 $\left.{ }^{-} \mathrm{CD} 8^{-} \mathrm{CD}^{-}\right)$thymocytes were subdivided into DN1-DN4 according to the expression of CD44 and CD25 (middle panel). Lower panel (green) shows the severe block at the transition DN3a (CD44 $\left.{ }^{-} \mathrm{CD} 25^{+} \mathrm{CD} 28^{-}\right)$to DN3b $\left(\mathrm{CD} 44^{-} \mathrm{CD} 25^{+} \mathrm{CD} 28^{+}\right)$in PAXX ${ }^{-1} \mathrm{Xlf}^{-1-}$ embryos. B220 ${ }^{+} \mathrm{CD} 19^{+} \mathrm{FL}$ cells were analyzed for the expression of $\mathrm{CD} 43$ that marks pro$\mathrm{B}$ cells (middle panel). In the lower panel, cells were gated on the $\mathrm{CD} 43^{+} \mathrm{B} 22 \mathrm{O}^{+} \mathrm{CD} 19^{+}$population and analyzed for ilgM expression. (b) Quantification of thymocyte subpopulations in the various PAXX/XIf genotypes. Mann-Whitney test was used for statistical analysis. (c) PCR strategy to analyze TCR $\beta$ rearrangement according to Gartner et al. ${ }^{29}$ and autoradiogram of PCR products revealed with the TCR-J $\beta$ probe demonstrating the absence of either $\mathrm{D} \beta-\mathrm{J} \beta$ or $\mathrm{V} \beta \mathrm{D} \beta \mathrm{J} \beta$ rearrangements in thymocytes from $\mathrm{PAXX} \mathrm{X}^{-1} \mathrm{XIf^{-1 } -}$ embryos. GAPDH-specific PCR was used as loading control

B-commited cell within the FL. This analysis clearly demonstrated an almost complete absence of detectable $\mathrm{VH}-\mathrm{DJH}$ rearrangement in FL from PAXX ${ }^{-1}-\mathrm{XIf}^{-1-}$ embryos (Figure 5c, lanes 9,10 , and 11) in contrast to wt animals. Interestingly, all embryos carrying the $\mathrm{XIf}^{-1-}$ genotype already demonstrated a decrease in V(D)J recombination efficiency, as judged by the decreased signal intensity of the PCR products, in line with the fall in IgM-expressing pro-B cells in these animals.

Our observations of an impaired $\mathrm{V}(\mathrm{D}) \mathrm{J}$ recombination in vivo in both $\mathrm{B}$ - and $\mathrm{T}$-cell lineages in $\mathrm{PAXX}^{-1-} \mathrm{XIf}^{-1-} \mathrm{E} 18.5$ embryos are in agreement with the reports of a similar malfunction in v-Abl-transformed pro-B-cell lines in vitro using chromosome-integrated $\mathrm{V}(\mathrm{D}) \mathrm{J}$ recombination substrates. ${ }^{13-15,22}$ Altogether, these experiments demonstrate that, although XIf and PAXX are largely dispensable for $V(D) J$ recombination, their concomitant defect sharply impairs the rearrangement of the TCR $\beta$ and $\operatorname{lgH}$ loci in T- and $B$-cell lineages, respectively, resulting in the block of their maturation in the thymus and the FL. This is consistent with the single ever born $\mathrm{PAXX}^{-1-} \mathrm{XIf}^{-1-}$ mouse that had no thymus and had a microspleen. ${ }^{12}$ We anticipate that the conditional ablation of these two genes in the hematopoietic system to bypass the embryonic lethality should result in live animals with a severe combined immunodeficiency phenotype characterized by the absence of mature $B$ and T lymphocytes.

We identified here a robust functional interplay in vivo between the two DNA repair factor paralogs XIf and PAXX, as evidenced by the synthetic lethality of their concomitant defect owing to a massive apoptosis of post-mitotic neurons and the negative impact on $V(D) J$ recombination in immature $B$ and $T$ lymphocytes. In that sense, PAXX-1-XIf ${ }^{-1-}$ DKO mice share most of the phenotypic characteristics of XRCC4 and DNALigase IV single-mutant mice. The survival of post-mitotic neurons and the development of the adaptive immune system both rely on efficient NHEJ as demonstrated in several animal models and human conditions. ${ }^{6}$ The impairment of these two functions specifically in PAXX ${ }^{-1-} \mathrm{XIf}^{-1-}$ animals, therefore, confirms the role of PAXX as a bona fide NHEJ factor. Others and we have previously reported that XIf, like PAXX, is largely dispensable during $\mathrm{V}(\mathrm{D}) \mathrm{J}$ recombination. ${ }^{17,18}$ We have recently highlighted the relationship between RAG2 and XIf as a mean to provide a two-tier mechanism ensuring the proper repair of DNAdsb generated during $V(D) J$ recombination and, hence to avoid genetic instability. ${ }^{14}$ A similar functional interaction between PAXX and XIf can be proposed to account for the unaffected $V(D) J$ recombination in $P A X X^{-1-}$ mice as 
a
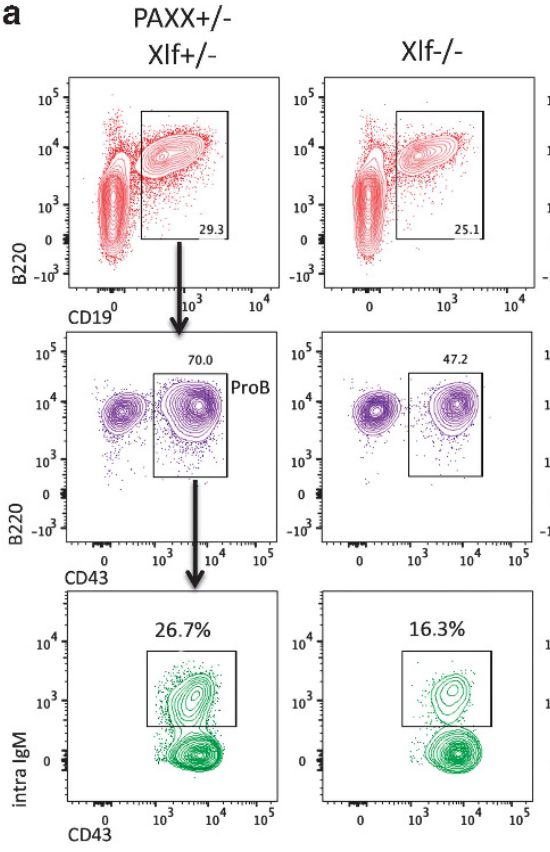

PAXX-/-
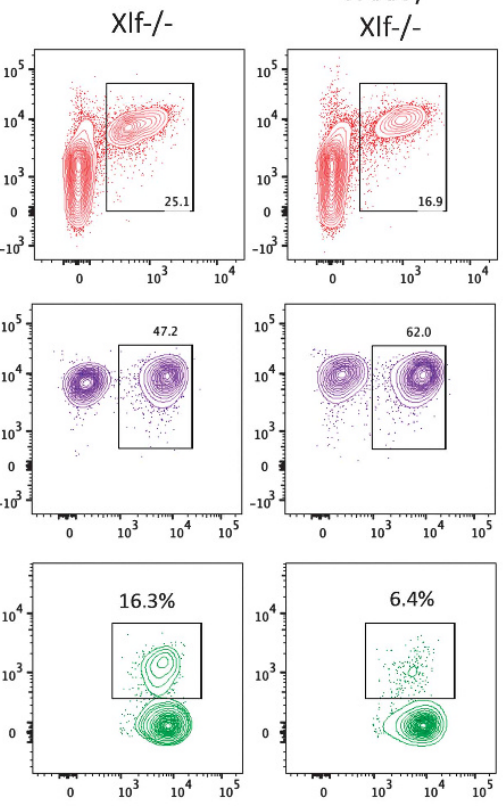

b

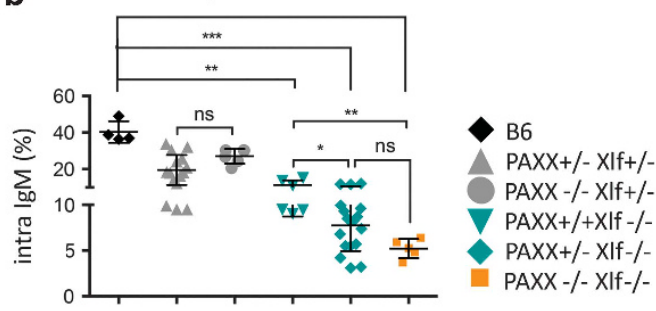

C
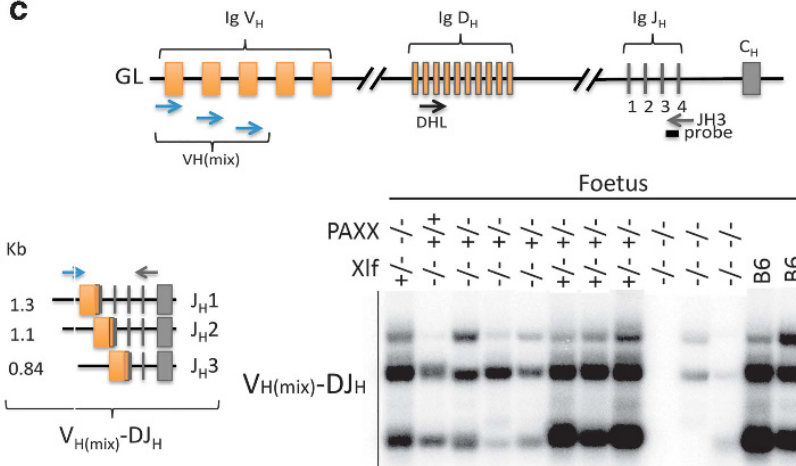

PAXX $\dot{+}+\frac{1}{+}+\frac{1}{+}+\frac{1}{+}+\frac{1}{+}+\frac{1}{+}$

Xlf $\frac{\dot{+}}{+}+\frac{1}{1}+\frac{1}{+}+\frac{1}{+}+\frac{1}{+}$

GAPDH

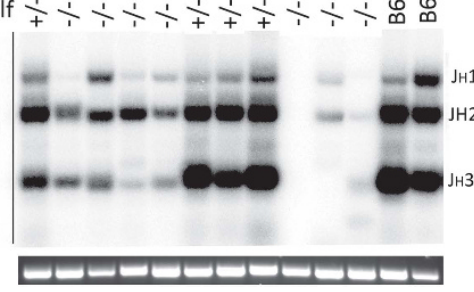

Figure $5 \mathrm{~V}(\mathrm{D}) \mathrm{J}$ recombination defect and impaired B-cell development in PAXX ${ }^{-/-} / \mathrm{Xlf}^{-/-}$E18.5 embryos. (a) Immunostaining of $\mathrm{FL}$ cells from PAXX ${ }^{-/-} \mathrm{XIf}^{-/-}$, $\mathrm{XIf}^{-/-}$, and PAXX ${ }^{-/} \mathrm{XIf}^{-/-}$E18.5 embryos. In the lower panel, B-lineage cells were gated on CD43+B220+ population and analyzed for intracytoplasmic lgM (ilgM) staining. (b) Quantification of ilgM-positive cells among various PAXX/XIf genotypes showing the severe deficit in PAXX ${ }^{-1-} \mathrm{XIf}^{-/-}$embryos. (c) PCR strategy to analyze IgH rearrangement according to Schlissel

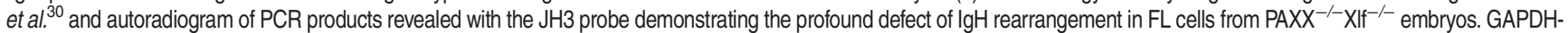
specific PCR was used as loading control

opposed to PAXX ${ }^{-1-} \mathrm{XIf}^{-1-}$ embryos. This would place PAXX on the same side as RAG2 in this safeguard mechanism. Accordingly, RAG2 and PAXX are epistatic, as their combined mutations do not impair $\mathrm{V}(\mathrm{D}) \mathrm{J}$ recombination in $\mathrm{V}$-Abl pro-B cells in vitro. ${ }^{14}$ Likewise, whereas $V(D) J$ recombination is severely compromised in $\mathrm{ATM}^{-/-} \mathrm{XIf}^{-/-}$mice, ${ }^{23}$ it is efficient in $\mathrm{ATM}^{-1-} \mathrm{RAG}^{\mathrm{CC}}$ mutated v-Abl cells, ${ }^{14}$ positioning ATM on the 'same side' as RAG2 and PAXX, opposite to Xlf. Indeed, $\mathrm{ATM}^{-1-} \mathrm{PAXX}^{-1-}$ animals do not present defect in the development of their adaptive immune system beyond that of the sole ATM deficiency as expected according to this model. ${ }^{12}$

\section{Materials and Methods}

gRNA design, cloning, and validation. Two guide RNA sequences were selected on exons 1 and 2 of the MUPAXX gene using the CRISPOR web tool (http://crispor.tefor.net/crispor.py). ${ }^{24}$ gRNA-overlapping restriction enzyme (RE) diagnostic sites near the Cas9 cleavage site were selected to facilitate mutagenesis screening and subsequent mouse genotyping (Supplementary Figures S1A and B). Double-stranded DNA oligonucleotides corresponding to the selected guide RNA were cloned into the pX330-U6-Chimeric_BB-CBh-hSpCas9 vector (the generous gift of Feng Zhang, Addgene, Cambridge MA, USA, \#42230) according to Zhang lab's recommendations. ${ }^{25}$ For mutagenesis scoring and mouse genotyping, genomic DNA surrounding the guide RNA target sequences were PCR-amplified (MuPAXX_F1: 5'-CAACCTTGAGTACCGCCCAT-3', MuPAXX_R1: 5'-CAACCTTGA GTACCGCCCAT-3', $500 \mathrm{bp}$ ) and the resulting PCR products digested with either $B s r B I$ or Sacl RE to analyze PAXX1 and PAXX2 mutagenesis, respectively (Supplementary Figure S1C and D). Undigested PCR products represent mutagenized DNA molecules. To validate CRISPR/Cas9 mutagenesis, the two gRNA expressing pX330 constructs were transfected into MEFs using the NEPA21 electroporator (Nepagene, Ichikawa-City, Chiba, Japan) with the following settings: pulse1 175v/5 ms/50 ms/2 ×/10\%/+-pulse2 20v/50 ms/50 ms/5 ×/40\%/+-. Genomic
DNA was recovered 5 days later and was analyzed using PCR-RE (Supplementary Figure S1C).

Generation of mutant mice. PAXX mutant mice were generated using CRISPR/Cas9 according to the protocol developed by Masahito Ikawa's laboratory. ${ }^{16}$ Briefly, the pX330-derived plasmid coding for Cas9 and the guide RNA were microinjected into mouse zygotes that were isolated from the ampullae of superovulated mice. For superovulation, 5 IU PMS and, $48 \mathrm{~h}$ later, 5 IU HCG was injected intraperitoneally into female B6/CBA F1 mice of $\sim 6$ weeks. Subsequently, they were mated with male B6/CBA F1 mice (C57B/6NCr and CBA mice: Charles River Laboratories, Saint-Germain-Nuelles, France). The day after, embryos were isolated and placed into M2 medium (Sigma, St. Louis, CA, USA) and the plasmid was injected at a concentration of $5 \mathrm{ng} / \mu \mathrm{l}$ into the pronucleus using a microscope (Nikon, Tokyo, Japan) with micromanipulators (Narishige, London, UK), Vacutip holding pipettes (Eppendorf, Hamburg, Germany), and homemade injection pipettes prepared from borosilicate capillary glass (Harvard Apparatus, Holliston, MA, USA) as well as a Femtojet apparatus (Eppendorf). Pseudopregnant mice received $\sim 20$ zygotes. The procedure was approved by the local ethical committee and the French Ministry of Education and Research (\#01501.03).

PAXX1 and PAXX2 mice were genotyped by PCR-RE (MuPAXX_F1, MuPAXX_R1, $500 \mathrm{bp}$ ) followed by $\mathrm{Bs}$ ßBI or Sacl RE digestion, respectively (Supplementary Figures $\mathrm{S} 1 \mathrm{C}$ and D). XIf KO mice were genotyped as previously described. ${ }^{17}$ PAXX1 and PAXX2 mice were backcrossed up to six times on C57BI/6 to segregate away any putative off-target mutation. PAXX/XIf double KO mice were generated by intercrossing $\mathrm{PAXX}^{-l-} / \mathrm{XIf}^{+/-}$or $\mathrm{PAXX}{ }^{+/-} / \mathrm{XIf}^{-1-}$ mice. All mice were sacrificed humanely.

Phleomycin and IR sensitivity assay. T lymphocytes were isolated from 6- to 10-week-old spleens and enriched for CD3+ cells using magnetic sorting (Dynabeads Untouched mouse T cells, Invitrogen). Purified T cells were stained with CellTrace BV421 fluorescent dye (Thermo-Fisher Scientific, Villebon sur Yvette, France). Overall, $3 \times 10^{5} \mathrm{~T}$ cells were plated in 48-well plates in triplicate in DMENGlutamax, FCS $10 \%, \beta$-Me $0.1 \%$, sodium pyruvate $1 \%$, penicillin and streptomycin $1 \%$, and NEAA $1 \%$. Culture plates were irradiated (0-4 Gy) and let for $4 \mathrm{~h}$ in incubator at $37^{\circ} \mathrm{C}$ to allow for DNAdsb repair. T cells were then activated by the 
addition of CD3/CD28-coated dynabeads (Thermo-Fisher Scientific) and $1000 \mathrm{u} / \mathrm{ml}$ IL2. After 4 days of culture, cells were stained with anti-TCR $\beta-\mathrm{PE}$ (Sony, Weybridge, Surrey, UK) and analyzed by FACS (LSR-Fortessa, Becton Dickinson, Rungis, France) to score the number of T-cell divisions through the dilution of the CellTrace dye (Figure 2a). The index of proliferation (EI) was calculated according to the following formula:

$\mathrm{El}=\sum_{0}^{i} \mathrm{Ni} /\left(\sum_{0}^{i} N i / 2^{i}\right)$

where $N$ represents the number of cells in each $(0-I)$ divided cell population. ${ }^{26}$ For each sample, the relative proliferative index after IR was calculated relative to the proliferation without IR and doseresponse curves were drawn to compare samples.

MEFs were obtained and transformed with SV40 Large T antigen (MEF-SV) as previously described. ${ }^{17}$ Phleomycin sensitivity assays were performed on MEF-SV using the IncuCyte Live Cell Analysis System (Essen BioScience, Ann Harbor, MI, USA). Briefly, MEF-SV of various genotypes were plated in triplicates at 3500 cells/ well in 48-well plates and incubated with increasing doses $(0,50,100$, and $200 \mathrm{ng} / \mathrm{ml})$ of Phleomycin. Real-time images of the wells were recorded ( $x 4$ lens) every $12 \mathrm{~h}$ over 7 days to monitor cell proliferation. A mask, which identifies visible objects in each image, was applied to quantify the occupied area (\% confluence) of every well at each time points (Supplementary Figure S2A). The final score of cell viability/proliferation was determined by integrating the area under the $\%$ confluence curves over time by using rectangular approximation as depicted in Supplementary Figure S2B). Given i, the various time points used for recording (from 1 to $n$ ), the growth index (GI), represented by the area under the curve, is calculated by the formula:

$G I=\sum_{i=1}^{n}(L * H 1)+(L * H 2) / 2$

For each experimental condition, cell viability is calculated relative to the $\mathrm{Gl}$ in the absence of drug (set as $100 \%$ growth) and plotted according to Phleomycin concentrations.

Immunoblotting, histology, and immunohistochemistry. Expression of PAXX was analyzed by western blotting on thymic protein extracts using rabbit polyclonal anti-C9orf142 antibody (ab126353, Abcam, Paris, France). Embryonic heads were fixed overnight at $4{ }^{\circ} \mathrm{C}$ by immersion in $4 \%$ paraformaldehyde and embedded in paraffin with a Tissu-tek processor (VIP, Leica, Wetzlar, Germany). Five $\mu \mathrm{m}$ coronal sections were then obtained using a microtome (Leica RM2125RT) and mounted onto glass slides for histologic analyses. After paraffin removal and citrate treatment, the brain sections were permeabilized with $0.5 \%$ Triton X-100 in phosphate-buffered saline (PBS) for $15 \mathrm{~min}$ and incubated for $2 \mathrm{~h}$ with $7.5 \%$ fetal bovine serum and $7.5 \%$ goat serum in PBS. The sections were incubated with rabbit anti-CC3 (Cell Signaling, Leiden, The Netherlands, 9661, $1: 200$ ) overnight at $4{ }^{\circ} \mathrm{C}$. After washing, the sections were incubated with goat antirabbit Alexa Fluor 488 or 594 conjugated secondary antibody (Thermo-Fisher Scientific, 1:400) for $1 \mathrm{~h}$. After washing, nuclear staining was achieved by incubation with 4'-6-Diamidino-2-phenylindole to quantify apoptosis induction by the detection of pyknotic nuclei. Slides were mounted under Fluoromount (Southern Biotechnologies Associates, Birmingham, AL, USA). Tissues were examined under a fluorescence microscope (Pathfinder, Nikon) with $\mathrm{a} \times 10$ or $\times 20$ objective in three channels (appearing red, green, and blue in all figures) as separate files. These images were then stacked with Photoshop software (Adobe, San Jose, CA, USA). All statistical analyses were performed on Prism (GraphPad, La Jolla, CA, USA, Version 7.00).

Immunophenotyping. Immunophenotyping of PAXX mice was performed as described. ${ }^{17}$ T-cell populations from the thymus and spleen were identified with antiCD8 (clone 5.3-6.7), anti-CD4 (GK1.5), and anti-CD3 (145-2C11). Splenic B cells were analyzed using anti-B220 (R6-60.2) and anti-lgM (II/41) and anti-CD19 (6D5). All antibodies were from BD Biosciences. Flow cytometry was performed on the BD LSR-Fortessa (Becton Dickinson, Rungis, France) and analyzed with FlowJo (Ashland, OR, USA). For immunophenotyping of PAXX/XIf DKO embryos, FLs and thymuses were microdissected under a binocular magnifying lens and passed through a 26-gauge needle of 1-ml syringe and filtered. For thymocytes, cell suspensions were stained with fluorescent-labeled antibodies from BD Biosciences (Becton Dickinson, Rungis, France) Anti-CD25 (clone PC61) and Anti-CD3e (145$2 \mathrm{C11}$ ) and from Sony anti-CD4 (GK1.5), anti-CD8 $\beta$ (YTS156.7.7), anti-CD44 (IM7),
anti-CD117 (2B8), and anti-CD28 (E18). For B-lineage, cell suspensions were stained with fluorescent-labeled antibodies from Biolegend (San Diego, CA, USA): anti-IgM (clone RMM-1) and anti-CD43 (S11), and from the Sony: anti-CD19APCCy7 (6D5) and anti-B220 (RA3-6B2). For intracellular IgM staining, cell suspensions were first labeled as above, fixed with the fixation buffer from eBioscience (ThermiFischer Scientific, Villebon sur Yvette, France) intracellular staining kit, and incubated 30 min with anti- IgM from Sony (clone RMM-1).

TCR $a$ repertoire study. TCR $\alpha$ repertoire analyses were performed by SMARTer 5' RACE CDNA amplification as previously described on thymocytes. ${ }^{17}$ CDR3 sequences were identified using LymAnalyzer ${ }^{27}$ and represented by circosplot using VDJtools. ${ }^{28}$ Each TRAV-TRAJ association was recorded in a FlowJobased file to calculate frequencies of TRAV and TRAJ proximal and distal gene usage. Statistical analyses were performed using Mann-Whitney non-parametric $t$-test under Prism v6.

TCR $\beta$ and $\operatorname{IgH} \mathbf{V ( D ) J}$ rearrangement analysis. TCR $\beta$ rearrangements (D-J $\beta 2$ and $V \beta 10-D-J \beta 2$ ) were analyzed by PCR on genomic DNA from E18.5 fetal thymuses of various genotypes according to Gartner et al. ${ }^{29}$ Briefly, 1 ing of thymic gDNA were amplified using primers TCRB-D2U-S 5'-GTA GGCACCTGTGGGGAAGAAACT-3', TCRB-J2D-A 5'-TGAGAGCTGTCTCCTACT ATCGATT-3', TCRB-V10-S 5'-GCGCTTCTCACCTCAGTCTTCAG-3', blotted, and hybridized using a PCR-derived TCR-J $\beta 2$ DNA probe (Jbeta2F-5'-GAATTCTTG GTAGCCCTTTTCTGC-3' and Jbeta2 R-5'-GGGTGGAAGCGAGAGATGT-3') as depicted on Figure $3 b$. For IgH rearrangements (VH-DJH) studies, FL CD19+ B-lineage cells were sorted on FACSArialll and analyzed by PCR on 1ng genomic DNA according to Schlissel et al. ${ }^{30}$ Input DNA was analyzed using a GAPDH PCR.

\section{Conflict of Interest}

The authors declare no conflict of interest.

Acknowledgements. We thank Catherine Cailleau (SEAT) for exceptional care of our mouse lines, Sophie Berissi for help in immunohistochemistry and Olivier Alibeu, Aurore Pouliet, and Christine Bole-Feyssot (Genomic facility, Imagine Institute) for their assistance in NGS. This work was supported by institutional grants from INSERM, the Institut National du Cancer (PLBI016-280), the Agence Nationale de la Recherche ('Investissement d'Avenir' program ANR-10-IAHU-01), and by grants from La Ligue Nationale contre le Cancer (Equipe Labellisée LA LIGUE), Pasteur Institute, ANR (Program REVIVE and grant Twothyme) to AC.

1. Sancar A, Lindsey-Boltz LA, Unsal-Kacmaz K, Linn S. Molecular mechanisms of mammalian DNA repair and the DNA damage checkpoints. Annu Rev Biochem 2004; 73: 39-85.

2. Jung D, Giallourakis C, Mostoslavsky R, Alt FW. Mechanism and control of V(D)J recombination at the immunoglobulin heavy chain locus. Annu Rev Immunol 2006; 24: 541-570.

3. Lieber MR. The mechanism of double-strand DNA break repair by the nonhomologous DNA end-joining pathway. Annu Rev Biochem 2010; 79: 181-211.

4. Gao Y, Sun Y, Frank KM, Dikkes P, Fujiwara Y, Seidl KJ et al. A critical role for DNA endjoining proteins in both lymphogenesis and neurogenesis. Cell 1998; 95: 891-902.

5. Frank KM, Sekiguchi JM, Seidl KJ, Swat W, Rathbun GA, Cheng HL et al. Late embryonic lethality and impaired V(D)J recombination in mice lacking DNA ligase IV. Nature 1998; 396 : 173-177.

6. de Villartay JP, Fischer A, Durandy A. The mechanisms of immune diversification and their disorders. Nat Rev Immunol 2003; 3: 962-972.

7. Alt FW, Zhang Y, Meng FL, Guo C, Schwer B. Mechanisms of programmed DNA lesions and genomic instability in the immune system. Cell 2013; 152: 417-429.

8. Xing $M$, Yang $M$, Huo W, Feng $F$, Wei $L$, Jiang $W$ et al. Interactome analysis identifies a new paralogue of XRCC4 in non-homologous end joining DNA repair pathway. Nat Commun 2015; 6: 6233 .

9. Ochi T, Blackford AN, Coates J, Jhujh S, Mehmood S, Tamura N et al. DNA repair. PAXX, a paralog of XRCC4 and XLF, interacts with Ku to promote DNA double-strand break repair. Science 2015; 347: 185-188.

10. Craxton A, Somers J, Munnur D, Jukes-Jones R, Cain K, Malewicz M. XLS (c9orf142) is a new component of mammalian DNA double-stranded break repair. Cell Death Differ 2015; 22: 890-897.

11. Tadi SK, Tellier-Lebegue $C$, Nemoz C, Drevet $P$, Audebert $S$, Roy $S$ et al. PAXX is an accessory c-NHEJ factor that associates with Ku70 and has overlapping functions with XLF. Cell Rep 2016; 17: 541-555.

12. Balmus G, Barros AC, Wijnhoven PW, Lescale C, Hasse HL, Boroviak K et al. Synthetic lethality between PAXX and XLF in mammalian development. Genes dev 2016; 30: 2152-2157. 
13. Kumar V, Alt FW, Frock RL. PAXX and XLF DNA repair factors are functionally redundant in joining DNA breaks in a G1-arrested progenitor B-cell line. Proc Natl Acad Sci USA 2016; 113: 10619-10624.

14. Lescale C, Abramowski V, Bedora-Faure M, Murigneux V, Vera G, Roth DB et al. RAG2 and $\mathrm{XLF} /$ Cernunnos interplay reveals a novel role for the RAG complex in DNA repair. Nat Commun 2016; 7: 10529

15. Liu X, Shao Z, Jiang W, Lee BJ, Zha S. PAXX promotes KU accumulation at DNA breaks and is essential for end-joining in XLF-deficient mice. Nat Commun 2017; 8: 13816.

16. Mashiko D, Fujihara $Y$, Satouh $Y$, Miyata $H$, Isotani A, Ikawa M. Generation of mutant mice by pronuclear injection of circular plasmid expressing Cas9 and single guided RNA. Sci Rep 2013; 3: 3355.

17. Vera G, Rivera-Munoz P, Abramowski V, Malivert L, Lim A, Bole-Feysot C et al. Cernunnos deficiency reduces thymocyte life span and alters the $T$ cell repertoire in mice and humans. Mol Cell Biol 2013; 33: 701-711.

18. Li G, Alt FW, Cheng HL, Brush JW, Goff PH, Murphy MM et al. Lymphocyte-specific compensation for XLF/cernunnos end-joining functions in $\mathrm{V}(\mathrm{D}) \mathrm{J}$ recombination. Mol Cell 2008; 31: 631-640

19. Roque T, Haton C, Etienne O, Chicheportiche A, Rousseau L, Martin L et al. Lack of a p21waf1/cip -dependent G1/S checkpoint in neural stem and progenitor cells after DNA damage in vivo. Stem cells 2012; 30: 537-547.

20. Teague TK, Tan C, Marino JH, Davis BK, Taylor AA, Huey RW et al. CD2 expression redefines thymocyte development during the pre-T to DP transition. Int Immunol 2010; 22 387-397.

21. Kajikhina K, Tsuneto M, Melchers F. B-lymphopoiesis in fetal liver, guided by chemokines Adv Immunol 2016; 132: 71-89.
22. Hung PJ, Chen BR, George R, Liberman C, Morales AJ, Colon-Ortiz P et al. Deficiency of $X L F$ and PAXX prevents DNA double-strand break repair by non-homologous end joining in lymphocytes. Cell Cycle 2017; 16: 286-295.

23. Zha S, Guo C, Boboila C, Oksenych V, Cheng HL, Zhang Y et al. ATM damage response and $\mathrm{XLF}$ repair factor are functionally redundant in joining DNA breaks. Nature 2011; 469: 250-254.

24. Haeussler M, Schonig K, Eckert H, Eschstruth A, Mianne J, Renaud JB et al. Evaluation of off-target and on-target scoring algorithms and integration into the guide RNA selection tool CRISPOR. Genome Biol 2016; 17: 148

25. Cong L, Ran FA, Cox D, Lin S, Barretto R, Habib N et al. Multiplex genome engineering using CRISPR/Cas systems. Science 2013; 339: 819-823.

26. Roederer M. Interpretation of cellular proliferation data: avoid the panglossian. Cytometry $A$ 2011; 79: 95-101.

27. Yu Y, Ceredig R, Seoighe C. LymAnalyzer: a tool for comprehensive analysis of next generation sequencing data of $\mathrm{T}$ cell receptors and immunoglobulins. Nucleic Acids Res 2016; 44: e31.

28. Shugay M, Bagaev DV, Turchaninova MA, Bolotin DA, Britanova OV, Putintseva EV et al. VDJtools: Unifying Post-analysis of T Cell Receptor Repertoires. PLOS Comput Biol 2015; 11: e1004503.

29. Gartner F, Alt FW, Monroe R, Chu M, Sleckman BP, Davidson L et al. Immature thymocytes employ distinct signaling pathways for allelic exclusion versus differentiation and expansion. Immunity 1999; 10: 537-546.

30. Schlissel MS, Corcoran LM, Baltimore D. Virus-transformed pre-B cells show ordered activation but not inactivation of immunoglobulin gene rearrangement and transcription. J Exp Med 1991; 173: 711-720.

\section{Supplementary Information accompanies this paper on Cell Death and Differentiation website (http://www.nature.com/cdd)}

